\title{
THE PERFORMANCE OF INDIUM TIN OXIDE FILMS DEPOSITED ON PLASTIC SUBSTRATE APPLIED FOR SOLAR-CELL BUOY
}

\author{
Chien-Kun Wang \\ Department of Electrical Engineering, National Taiwan Ocean University, Keelung 20224, Taiwan, R.O.C. \\ Jyh-Jier Ho \\ Department of Electrical Engineering, National Taiwan Ocean University, Keelung 20224, Taiwan, R.O.C., \\ jackho@mail.ntou.edu.tw \\ Sung-Jen Nien \\ Department of Electrical Engineering, National Taiwan Ocean University, Keelung 20224, Taiwan, R.O.C. \\ Yuang-Tung Cheng \\ Department of Electrical Engineering, National Taiwan Ocean University, Keelung 20224, Taiwan, R.O.C. \\ William Lee \\ Electronics and Optoelectronics Research Laboratories, Industrial Technology Research Institute, Hsinchu 31040, \\ Taiwan, R.O.C.
}

See next page for additional authors

Follow this and additional works at: https://jmstt.ntou.edu.tw/journal

Part of the Electrical and Computer Engineering Commons

\footnotetext{
Recommended Citation

Wang, Chien-Kun; Ho, Jyh-Jier; Nien, Sung-Jen; Cheng, Yuang-Tung; Lee, William; Lu, Chih-Chiang; Yau, Bao-Shun; Tsai, Hsing-Wang; and Chang, Chung-Cheng (2010) "THE PERFORMANCE OF INDIUM TIN OXIDE FILMS DEPOSITED ON PLASTIC SUBSTRATE APPLIED FOR SOLAR-CELL BUOY," Journal of Marine Science and Technology. Vol. 18: Iss. 6, Article 6.

DOI: $10.51400 / 2709-6998.1940$

Available at: https://jmstt.ntou.edu.tw/journal/vol18/iss6/6

This Research Article is brought to you for free and open access by Journal of Marine Science and Technology. It has been accepted for inclusion in Journal of Marine Science and Technology by an authorized editor of Journal of Marine Science and Technology.
} 
THE PERFORMANCE OF INDIUM TIN OXIDE FILMS DEPOSITED ON PLASTIC SUBSTRATE APPLIED FOR SOLAR-CELL BUOY

\section{Authors}

Chien-Kun Wang, Jyh-Jier Ho, Sung-Jen Nien, Yuang-Tung Cheng, William Lee, Chih-Chiang Lu, Bao-Shun Yau, Hsing-Wang Tsai, and Chung-Cheng Chang 


\title{
THE PERFORMANCE OF INDIUM TIN OXIDE FILMS DEPOSITED ON PLASTIC SUBSTRATE APPLIED FOR SOLAR-CELL BUOY
}

\author{
Chien-Kun Wang*, Jyh-Jier Ho*, Sung-Jen Nien*, Yuang-Tung Cheng*, \\ William Lee**, Chih-Chiang Lu**, Bao-Shun Yau**, Hsing-Wang Tsai**, \\ and Chung-Cheng Chang*
}

Key words: polyethyene terephthalate (PET), indium tin oxide (ITO), detergent, solar-cell buoy.

\begin{abstract}
In this paper, we report the indium tin oxide (ITO) films deposited on the polyethyene terephthalate (PET) substrate, which surface is treated with detergent solution. The ITO films are deposited on room temperature by direct current (DC) magnetron sputtering from a ceramic target of a $90 \%$ In-10\% Sn alloy. The deposited opto-electric ITO films on PET with detergent treatment are $83.4 \%$ average visible transparency, and $5.8 \times 10^{-4} \Omega$-cm resistivity, respectively.

And then, we use the spin coating to form the polymer solar cell. Under optimal conditions of surface treatment and film deposition, the experimental result shows $2.12 \%$ of the power conversion efficiency (PCE), which is suitable for the solarcell buoy applications.
\end{abstract}

\section{INTRODUCTION}

Since Taiwan is surrounded by ocean which located in the central of Asia-Pacific area. It is important for international trade that the marine ship navigated by buoy. Generally speaking, the buoy has two functions: one is used for guidance and caution of the navigation, the other is used for the collection and transmission of the oceanic information. Because the marine power supply is difficult to implement, only a few buoy use wind power generation, while the majority of buoys use electric power generated by solar cell.

Nowaways, the marine solar cell mainly uses Si substrate. Because the marine meteorology is severe and will crack $\mathrm{Si}$

Paper submitted 05/22/09; revised 04/27/10; accepted 09/10/10. Author for correspondence: Jyh-Jier Ho (e-mail: jackho@mail.ntou.edu.tw).

*Department of Electrical Engineering, National Taiwan Ocean University, Keelung 20224, Taiwan, R.O.C.

**Electronics and Optoelectronics Research Laboratories, Industrial Technology Research Institute, Hsinchu 31040, Taiwan, R.O.C. crystal solar cell by serious bursts, hence, increase the overall cost of marine solar cell. Because plastic substrate has better capability in abosoring crash, easier to be produced in greater area, better production process and, lower material cost [5]. This may prevent solar cell from damaged by server crack.

Because indium tin oxide (ITO) compound has high visible transparency, excellent merit $[1,6,7]$ and high conductivity as well as high work function, therefore we select the ITO compound as the part electrode layer. In this experiment, we reported untreated and detergent surface treatment on the polyethylene terephthalate (PET) substrate. Then, the ITO films were deposited on substrate and rotate the carrier board and spread ITO to produce polymer solar cell.

\section{EXPERIMENTAL}

In this research, we use PET substrate with thickness of 125 $\mu \mathrm{m}$ produced by Kimoto Corporation. First the substrate is separated into two groups - unprocessed plate and plate with surface cleaned by cleaner. The $\mathrm{KOH}$ solution was used as a detergent. In the experimental, thin films of ITO by direct current (DC) magnetron sputtering from a ceramic target of a $90 \%$ In-10\% Sn alloy deposited onto two kind of plastic substrate at room temperature. During ITO films deposition period we pass over the argon and the little oxygen separately. Before splashing plates the target material deposition thin films, we inject oxygen for first 5 minutes to make the gas stabilized, only then we start to splash ITO thin films on the plate. After the ITO thin films are splashed, the plates are separated into three groups - untreated, detergent, detergent and uv-ozone treatment. We used coating the PEDOT:PSS and active layer, respectively.

We set the coating speed as $4000 \mathrm{rpm}$ with duration of 1 minute to spread PEDOT:PSS resolver on ITO films. The active component layer uses highly stabile and most popular poly-3-hexthiophene (P3HT) and [6]-phenyl- C61 butyric acid methyl ester (PCBM) [2,8]. The resolver of solar cell active component layer consist of P3HT and PCBM with the ratio 


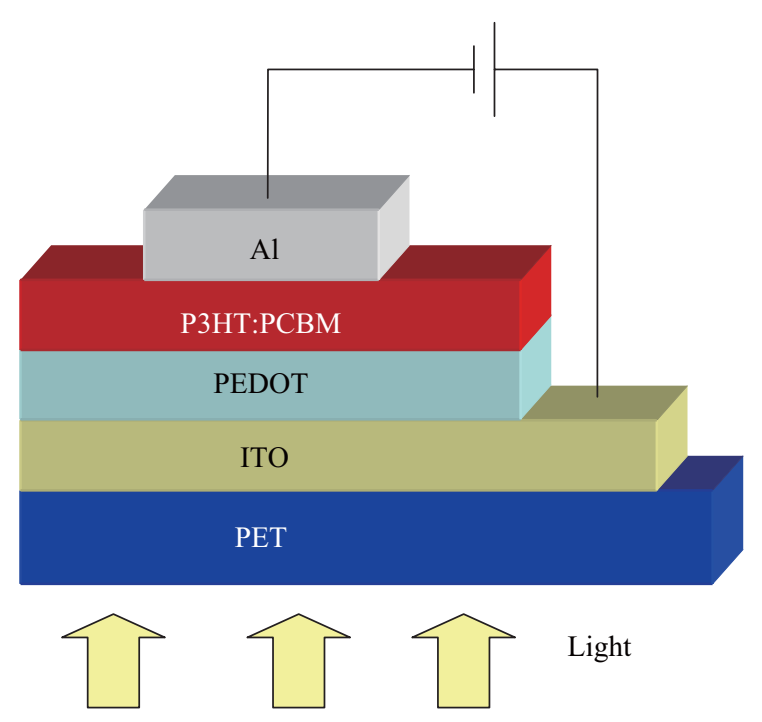

Fig. 1. The component structure of polymer solar cell.

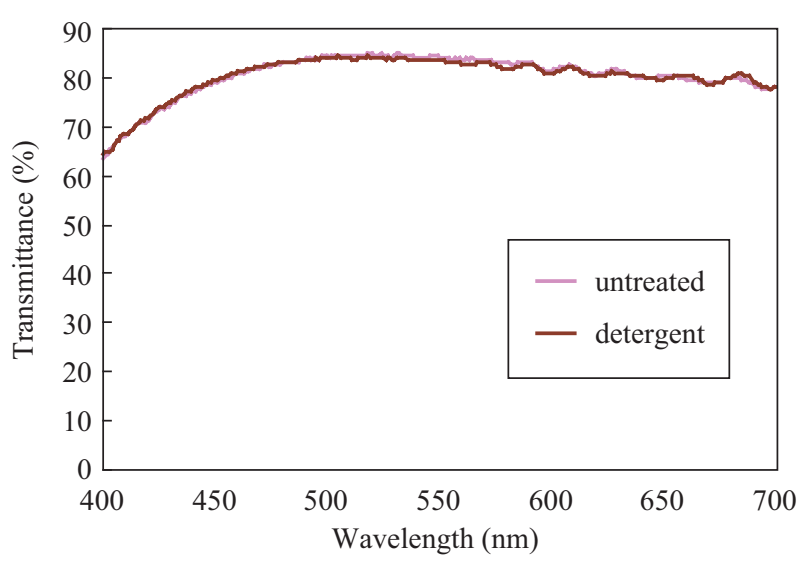

Fig. 2. The optical spectrum of different process with ITO films.

of 1-to-1 is put into 1,2-dichlorobenzene (DCB) and heat up by $70^{\circ} \mathrm{C}$ for 1 hour. Afterward, we will spread prepared P3HT:PCBM in the container by rotational speed of $600 \mathrm{rpm}$ for 1 minute on PEDOT. Then the solar cell active component layer is spread with aluminum electrode in evaporation machine. The overall component structure is shown in Fig. 1.

For the efficiency of solar cell, we measure it with AM1.5 as simulated sun light.

\section{RESULTS AND DISCUSSIONS}

In Fig. 2, ITO films with untreated and detergent treatment on PET substrate shows $84 \%$ and $83.4 \%$ at wavelength of 400 $\mathrm{nm}$ to $700 \mathrm{~nm}$. In addition, we used four point probe measure separable to obtain $6.1 \times 10^{-4} \Omega$ and $5.8 \times 10^{-4} \Omega$-cm resistivity.

We observe via Atomic Force Microscopy (AFM) and found the roughness of ITO surface increased due to the untreated PET surface is slippery and not easy to deposit which causes

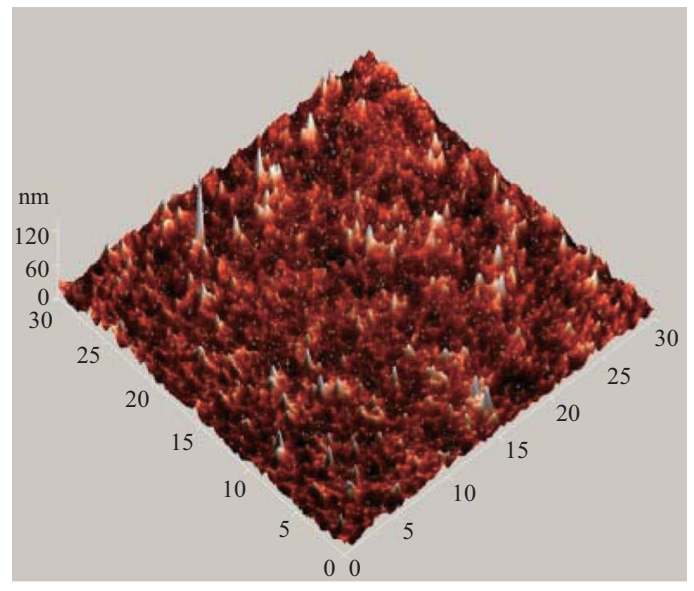

(a)

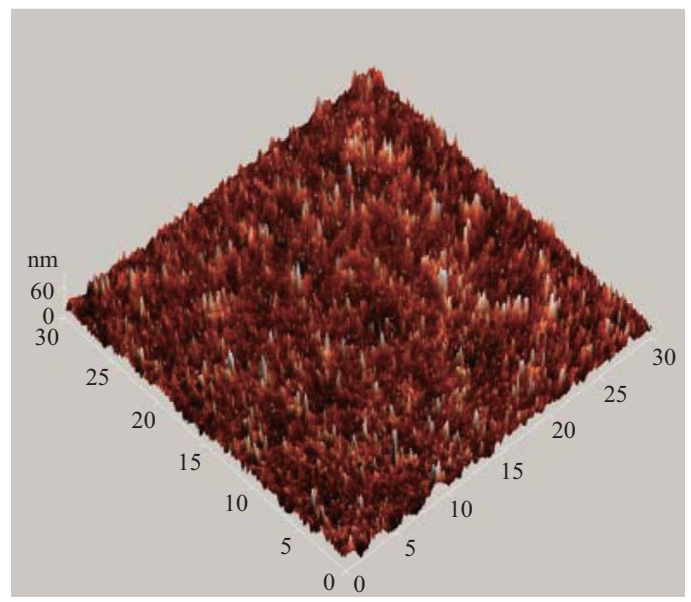

(b)

Fig. 3. The AFM of (a) untreated PET substrate and (b) treated PET.

the adhesiveness question. As shown in Fig. 3(a), the untreated PET has $\mathrm{Ra}=6.5 \mathrm{~nm}$. As shown in Fig. 3(b), the treated PET has $\mathrm{Ra}=8.0 \mathrm{~nm}$. As shown in Fig. 4(a), the treated PET with deposition of untreated ITO films has $\mathrm{Ra}=$ $8.8 \mathrm{~nm}$. As shown in Fig. 4(b), the treated PET with deposition of treated ITO films has $\mathrm{Ra}=9.2 \mathrm{~nm}$.

Figures 5 and 6 show the SEM photos of the surface morphologies of the deposited ITO films with/without surface treatment of PET substrate. From these films' images, there is no any crack with high-quality films on PET substrates even after surface treatment.

ITO films were deposited on treated plastic PET substrates by DC magnetron sputter system using an oxidized target with $\mathrm{In}_{2} \mathrm{O}_{3}$ and $\mathrm{SnO}_{2}$ at a weight proportion of 9:1. The distance between target and substrate was approximately $4 \mathrm{~cm}$. The total working pressure of $4 \times 10^{-6}$ torr consisted of a gas mixture of argon (Ar) and oxygen $\left(\mathrm{O}_{2}\right)$, which was maintained at a fixed $\mathrm{O}_{2}$ flow rate of $1 \mathrm{sccm}$. The Ar flow rate was adjusted in the range of 20-60 sccm during different treatment substrate film growth. All films with a thickness of around $100 \mathrm{~nm}$ were grown at room temperature. ITO films were deposited at 


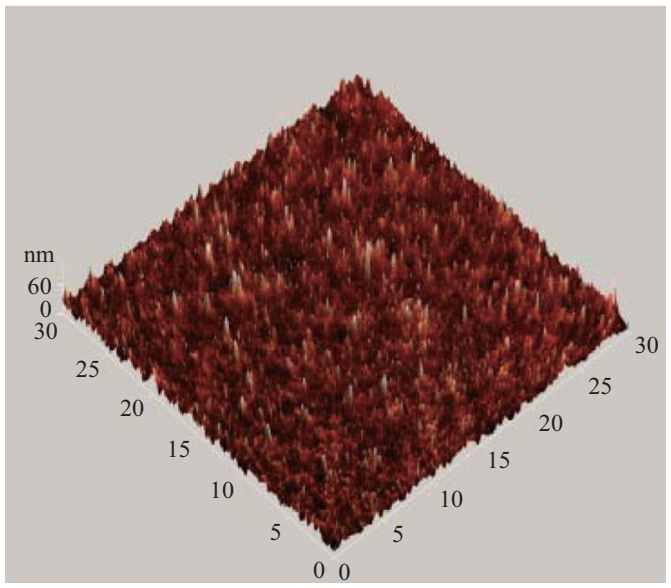

(a)

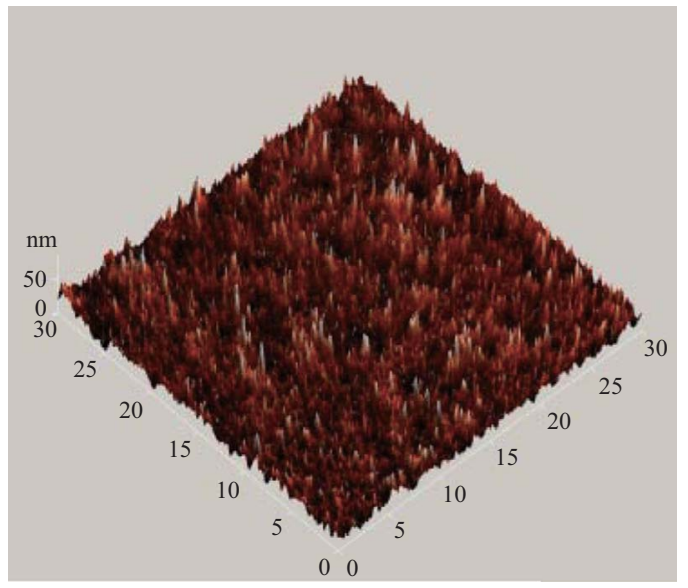

(b)

Fig. 4. The AFM of (a) untreated ITO films and (b) treated ITO films deposition on treated PET substrate.

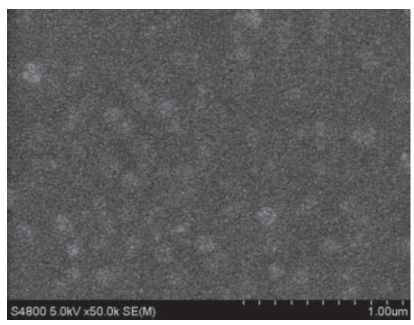

(a)

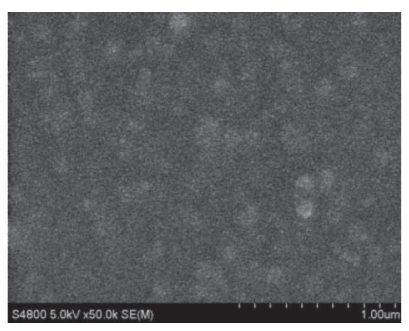

(b)
Fig. 5. The SEM of (a) untreated and (b) treated PET substrate.

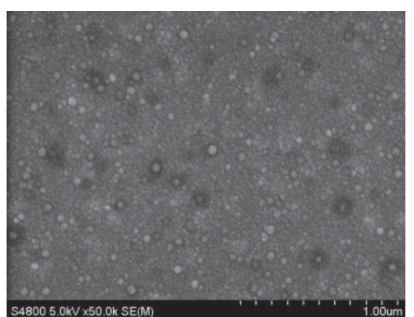

(a)

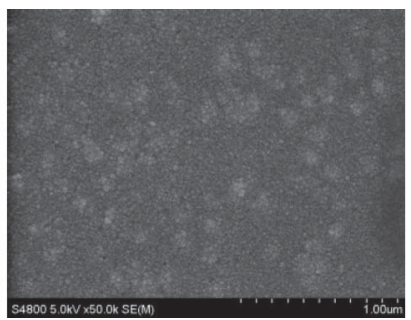

(b)
Fig. 6. The SEM of (a) untreated ITO films and (b) treated ITO films deposition on treated PET substrate.

substrates with different surface treatment under the $40 \mathrm{~W}$ power with different argon. Figure 7 shows the resistivity and transmittance dependences of Ar gas flow rate. While the Ar gas increasing, the resistivity will increase but the transmittance will decrease. As a result, the transmittance is greater than $80 \%$ and resistivity changes a little $\left(6 \times 10^{-4} \Omega-\mathrm{cm}\right)$ for $\mathrm{Ar}$ gas flow is $20 \mathrm{sccm}$.

The contact angle is just only for adhesiveness test, when the contact angle is smaller than 90 degrees, this represents the surface is the water affinity. When the contact angle is lower, this represents the surface is the more humid. [4]. As shown in Fig. 8, when we use cleaner to clean surface, it can make the

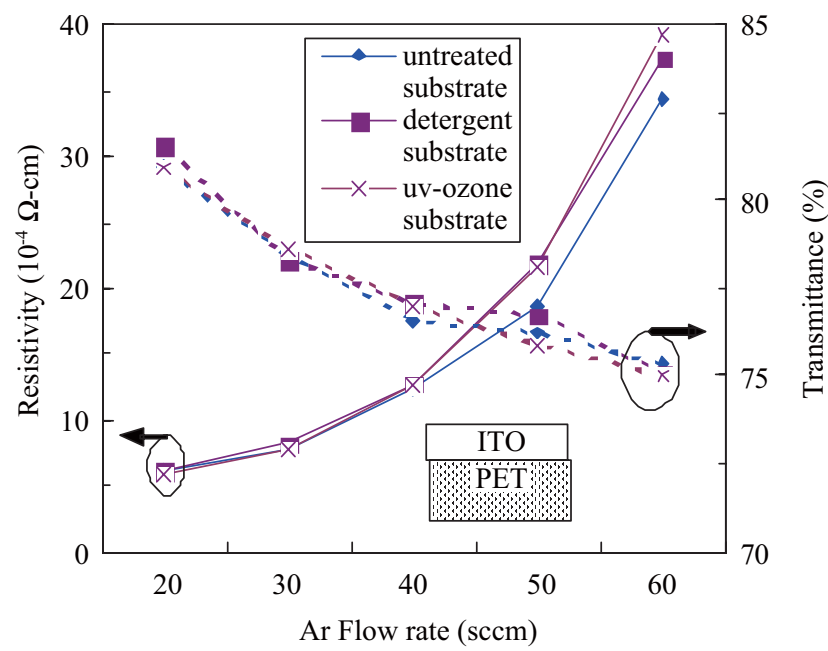

Fig. 7. The resistivity and transmittance of the ITO deposited on a PET substrate with different surface treatment.

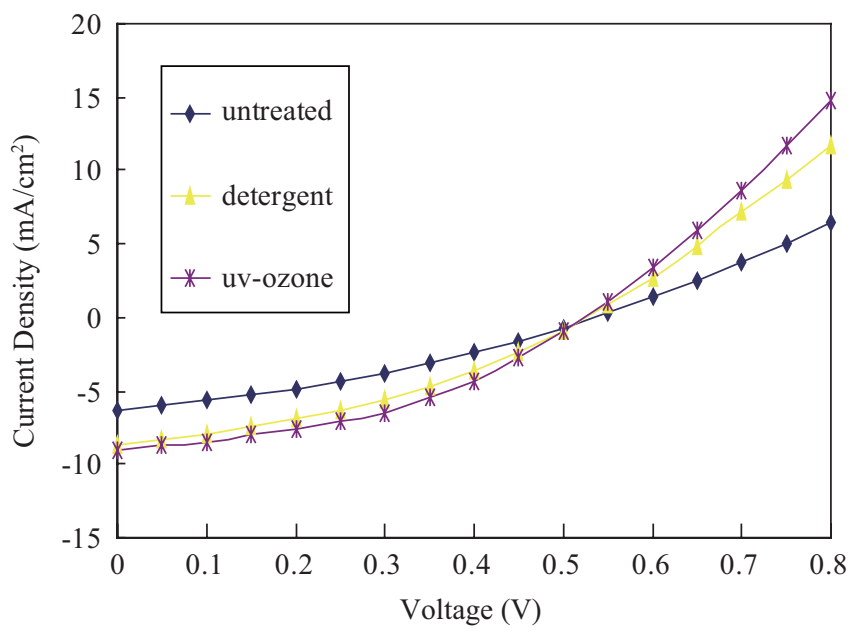

Fig. 8. The contact angle of ITO films on untreatment and treatment PET. 


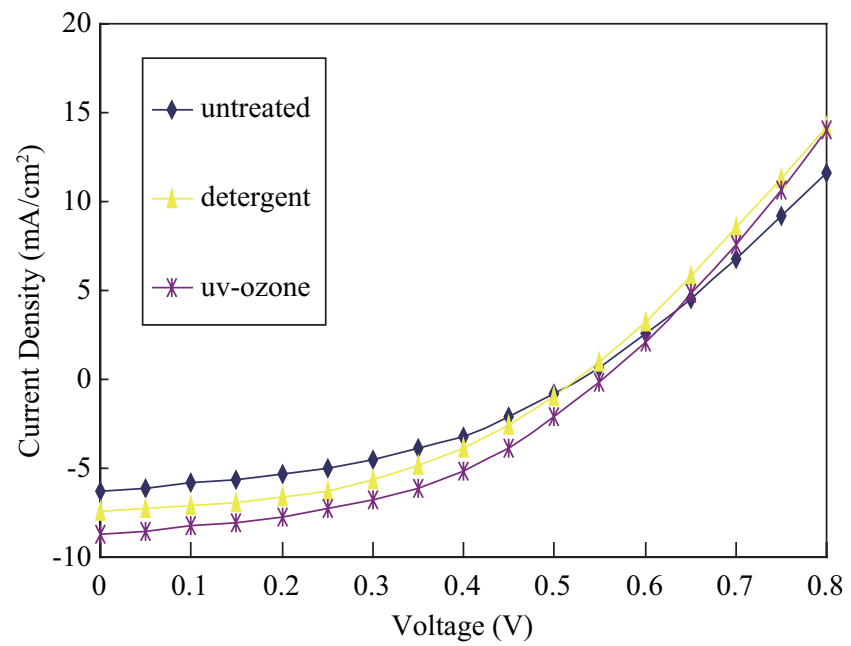

Fig. 9. The efficiency of polymer solar cell by different surface treatment with ITO films of untreatment PET.

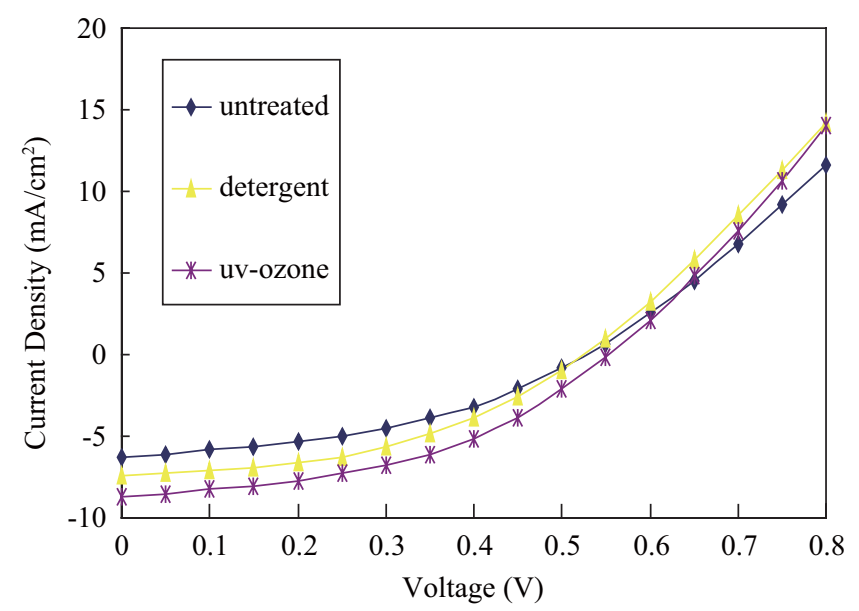

Fig. 10. The efficiency of polymer solar cell by different surface treatment with ITO films of treatment PET.

contact angle to dropdown and to increase the superficial adhesiveness. If we use both the detergent and uv-ozone to handle surface process, then we can get the best result. It is mainly because uv-ozone can not only increase the ITO films the work function but also to generate $\mathrm{OH}$ bond to increase the water affinity of the surface [3]. As shown in Figs. 9 and 10, we can find as the contact angle to be lower, the transfer efficiency of the solar cell will also slowly increase.

In addition, we increase power conversion efficiency (PCE) of the polymer solar cell by using PET surface treatment and ITO films surface treatment. From Table 1, we can find the untreated ITO films of PET to obtain $1.12 \%$ power conversion efficiency. After we use detergent to add the uv-ozone processing on ITO films, the power conversion efficiency may achieve $1.93 \%$, which improved about $72.3 \%$ as compared with that of the untreated substrate. From Table 2, we can find the processed ITO films of PET to obtain $1.37 \%$ solar energy
Table 1. The performance of the polymer solar cell by different surface treatment with ITO films on the untreated PET substrate.

\begin{tabular}{|c|c|c|c|}
\hline & Untreatment & treatment & $\begin{array}{c}\text { treatment with } \\
\text { uv-ozone }\end{array}$ \\
\hline $\mathrm{Jsc}\left(\mathrm{mA} / \mathrm{cm}^{2}\right)$ & 6.42 & 8.59 & 9.0 \\
\hline $\mathrm{Voc}(\mathrm{V})$ & 0.536 & 0.529 & 0.524 \\
\hline $\mathrm{FF}$ & 0.32 & 0.37 & 0.40 \\
\hline $\mathrm{PCE}(\%)$ & 1.12 & 1.68 & 1.93 \\
\hline
\end{tabular}

Table 2. The performance of the polymer solar cell by fferent surface treatment with ITO films on the detergent treated PET substrate.

\begin{tabular}{|c|c|c|c|}
\hline & Untreatment & treatment & $\begin{array}{c}\text { treatment with } \\
\text { uv-ozone }\end{array}$ \\
\hline $\mathrm{Jsc}\left(\mathrm{mA} / \mathrm{cm}^{2}\right)$ & 6.25 & 7.40 & 8.76 \\
\hline $\mathrm{Voc}(\mathrm{V})$ & 0.53 & 0.523 & 0.553 \\
\hline $\mathrm{FF}$ & 0.415 & 0.441 & 0.438 \\
\hline $\mathrm{PCE}(\%)$ & 1.37 & 1.70 & 2.12 \\
\hline
\end{tabular}

transfer efficiency, After we use detergent adds the uv-ozone processing on ITO films, the PCE may achieve $2.12 \%$, which improved about $54.7 \%$ as compared with that of the untreated substrate.

\section{CONCLUSION}

In summary, the developed opto-electric ITO films on PET with untreatment and detergent treatment are $84 \%$ and $83.4 \%$ average visible transparency, $6.1 \times 10^{-4} \Omega$-cm and $5.8 \times 10^{-4}$ $\Omega$-cm resistivity, respectively. These ITO films are above the standard of the electro-optical applications.

We provide the power source of buoy with polymer solar cell on PET. Because polymer solar cell has the advantages of low-cost, easy production and excellent endurance in crash, it will be able to replace Si solar cell in the near future. The PCEs of the developed solar cell are $1.93 \%$ and $2.12 \%$ after applying the optimization process with cleaner and uv-ozone to untreated and surface-processed PET. Those data are suitable for the solar-cell buoy applications.

\section{REFERENCES}

1. Betz, U., Olsson, M. K., Marthy, J., and Escola, M. F., "On the synthesis of ultra smooth ITO thin films by conventional direct current magnetron sputtering," Thin Solid Films, Vol. 516, pp. 1334-1340 (2008).

2. Hauch, J. A., Schilinsky, P., Choulis, S. A., Childers, R., Biele, M., and Brabec, C. J., "Flexible organic P3HT:PCBM bulk-heterojunction modules with more than 1 year outdoor lifetime," Solar Energy Materials \& Solar Cells, Vol. 92, pp. 727-731 (2008).

3. Nie, H.-Y., Walzak, M. J., and Mcintyre, N. S., "Atomic force microscopy study of UV/ozone treated polyproplene films," Polymer Surface Modification: Relevance to Adhesion, Vol. 2, pp. 377-392 (2000). 
4. Oh, B. S., Jung, Y. J., Oh, Y. J., Yoo, Y. S., and Kang, J.-W., “Application of ozone, UV and ozone/UV processes to reduce diethyl phthalate and its estrogenic activity," Science of Total Environment, Vol. 367, pp. 681-693 (2006).

5. Peumans, P., Uchida, S., and Forrest, S. R., "Efficient bulk heterojunction photovoltaic cells using small-molecular-weight organic thin films," $\mathrm{Na}$ ture, Vol. 425, pp. 158-162 (2003).

6. Wang, L.-M., Chen, Y.-J., and Liao, J.-W., "Characteristics of indium-tin oxide thin films grown on flexible plastic substrate at room temperature,"
Journal of Physics and Chemistry of Solids, Vol. 69, pp. 527-530 (2008).

7. Yang, C.-H., Lee, S.-C., Lin, T.-C., and Chen, S.-C., "Electrical and optical properties of indium tin oxide films prepared on plastic substrate by radio frequency magnetron sputtering," Thin Solid Films, Vol. 516, pp. 19841991 (2008).

8. Zhokhavets, U., Erb, T., Hoppe, H., Gobsch, G., and Sariciftci, N. S., "Effect of annealing of poly(3-hexylthiophene)/fullerene bulk heterojunction composites on structural and optical properties," Thin Solid Films, Vol. 496, pp. 679-682 (2006). 